\title{
Schistosomiasis and Associated Infections
}

\section{JR Lambertucci ${ }^{+}$, AAM Rayes, JC Serufo, R Gerspacher-Lara, G Brasileiro- Filho, R Teixeira, CMF Antunes, AM Goes*, PMZ Coelho**}

\author{
Departamento de Clínica Médica, Faculdade de Medicina *Departamento de Imunologia e Bioquímica \\ **Departamento de Parasitologia, ICB,UFMG, Av. Alfredo Balena 190, 30130-100 \\ Belo Horizonte, MG, Brasil
}

In hospital-based series viral hepatitis B has been frequently described in association with schistosomiasis whilst in field-based studies the association has not been confirmed. The association between schistosomiasis and Salmonella bacteraemia has been well documented. More recently, acute schistosomiasis has been shown to be a facilitating factor in the genesis of pyogenic liver abscesses caused by Staphylococcus aureus. New evidences indicate an interaction between the acquired immunodeficiency syndrome (AIDS) and schistosomiasis. In this paper, data on the association of schistosomiasis with other infections are updated.

Key words: schistosomiasis - salmonellosis - staphylococci - AIDS - liver abscesses

\section{ASSOCIATION WITH VIRAL HEPATITIS B}

Patients with hepatosplenic schistosomiasis have been reported to be more frequent carriers of hepatitis B surface antigen than patients with other forms of schistosomiasis or uninfected individuals (Lambertucci 1993).

It is generally accepted that Schistosoma mansoni infection alone does not lead to cirrhosis or chronic active hepatitis. Interaction between hepatitis B virus (HBV) and $S$. mansoni infection was suggested to cause a more serious form of chronic liver disease (Bassily et al. 1979). Liver biopsy studies have shown a significant increase of chronic hepatitis and hepatic decompensation in S. mansoni infected subjects (Lyra et al. 1976, Chen \& Mott 1988). Patients with this dual infection more often develop jaundice, intractable ascites and hepatic failure. The clinical management is more complicated and the prognosis more guarded than for chronic hepatosplenic schistosomiasis alone.

Different reasons have been advanced to account for the S. mansoni-hepatitis B association: (1) impaired cell-mediated immunity which reduces host resistance (Lyra et al. 1976, Colley et al. 1986); (2) low socioeconomic conditions and educational levels which increase the risk of exposure; (3) repeated treatments in the past with in-

Partially supported by $\mathrm{CNPq} / \mathrm{Brazil}$.

${ }^{+}$Corresponding author. Fax: +55-31-273.4985. E-mail: lamber@net.em.com.br

Received 4 May 1998

Accepted 31 August 1998 travenous or parenteral drugs or blood transfusions (Madwar et al. 1989).

Some patients were negative for HBsAg but had the typical liver biopsy histological picture of chronic active hepatitis (Coelho et al. 1985); the role of hepatitis $\mathrm{C}$ or the existence of other aetiological factors should be investigated (Pereira et al. 1997).

In a controlled study, treatment of schistosomiasis with oxamniquine did not result in disappearance of the antigenaemia (Lyra et al. 1976).

Studies from Egypt suggest that patients with hepatosplenic schistosomiasis and infant born to mothers with active schistosomiasis present a weak or failed response to the hepatitis B vacccine (Ghaffar et al. 1989, 1990). These studies await confirmation.

The positive relationship between HBV and $S$. mansoni infection has been questioned by a few investigators (Serufo \& Lambertucci 1997). Domingo et al. (1983) studying a nonhospitalized population found no difference in HBV exposure and HB surface antigen positivity between individuals with $S$. japonicum infection, including hepatosplenic disease, and individuals without schistosomiasis. A lack of association between schistosomiasis mansoni and HB has also been reported from Egypt (Hyams et al. 1986, Eltoum et al. 1991).

Summing-up, in hospital-based studies the carrier rate of $\mathrm{HBV}$ in patients with hepatosplenic schistosomiasis was higher than in the controls, whilst in field-based studies an association between these organisms has not been found (Serufo 1997). Further observations with well-designed studies are necessary to clarify this controversy. 


\section{ASSOCIATION WITH SALMONELLA}

Chronic persistent Salmonella bacteraemia has been described in association with $S$. mansoni infection (Neves \& Martins 1967, Salih et al. 1977). The most common characteristics of the clinical syndrome are: (i) an indolent febrile disease (from several weeks to a few years); (ii) bacteraemia with one of many species of the genus Salmonella; (iii) chronic active schistosomiasis. It occurs most commonly in males between the ages of 10 and 30 years. Patients complain of fatigue, malaise, weight loss and fever. Even with bacteraemia for many months they do not look toxaemic; hepatosplenomegaly has been described in most cases, but many patients with the hepatointestinal form have also presented with the syndrome. Oedema and a petechial rash on the lower limbs are common. Prostration and delirium never occur. Localized infections, as are found in the osteomyelitis of sickle cell disease, and chronic cholecystitis do not occur. The clinical features of this peculiar association have been described as being more like kalaazar than typhoid fever (Lambertucci et al. 1991a).

Salmonella are easily recovered from the blood; in $25 \%$ of cases they have also been isolated from the faeces or urine. The Widal test, positive in $25 \%$ of cases, is not helpful in the diagnosis of the syndrome (Lambertucci et al. 1985a). Eosinophilia increases after treatment with antibiotics.

The bacteria are found in the tegument or in the intestinal tract of $S$. mansoni adult worms. The role of schistosomes as a source and vehicle of Salmonella infection has been suggested (Lo Verde et al. 1980), and sera from patients with hepatosplenic schistosomiasis were found to have reduced antibody activities against $S$. typhi and $S$. cholerasuis compared with normal controls (Rocha et al. 1971, Muniz-Junqueira et al. 1996).

Mortality is rare, and the response to antibiotic therapy is dramatic. However, recurrent Salmonella bacteraemia is common if the underlying schistosome disease is not treated. Effective treatment of schistosomiasis alone deprives the Salmonella of favourable foci for growth and eliminates both infections in more than $90 \%$ of the cases (Lambertucci et al. 1985b).

Renal involvement is common in patients with Salmonella-S. mansoni association. At least two patterns of clinical and histological renal involvement have been described. Barsoum et al. (1977), in Egypt, categorized their Salmonella-positive cases in two groups: (1) those with clinical, laboratory and histological evidence of interstitial nephropathy, without glomerular involvement, that probably resulted from Salmonella pyelonephritis. These findings have not been confirmed by
Brazilian studies (Lambertucci et al. 1988), and before accepting this as a distinct pattern it would be desirable to define the importance of concomitant $S$. haematobium infection in the pathologic findings reported in patients from Egypt; (2) those with overt glomerular disease, usually proliferative glomerulonephritis with minimal or no basement membrane thickening, being the nephritic syndrome the presenting clinical picture (Lambertucci et al. 1988).

The association of S. mansoni with Escherichia coli has also been described (Teixeira et al. 1976, Farid et al. 1984). After months of febrile attacks, treatment with co-trimoxazole or amoxycillin followed by antischistosomal drugs resulted in cure.

Rocha et al. (1968) inoculated E. coli into mice previously infected with $S$. mansoni and observed bacteraemia and liver abscesses in the experimental group. The formation of abscesses was interpreted as being derived from suppurative cholangitis.

The number of cases of bacteraemia due to Gram-negative bacteria other than Salmonellae should not increase since it is known that most Gram-negative organisms parasitize and kill the schistosomes (Ottens \& Dickerson 1972).

\section{ASSOCIATION WITH STAPHYLOCOCCUS AUREUS}

Graham and Orr (1950) described the case of an English Army officer who developed a S. aureus liver abscess associated with schistosomiasis and suggested that the liver damage caused by schistosomiasis may have paved the way for a subsequent pyogenic infection. Lambertucci et al. (1990) described the cases of two children with skin pustules and acute schistosomiasis who also developed multiple pyogenic liver abscesses caused by $S$. aureus. Liver abscesses were duplicated in the murine model of schistosomiasis when mice were injected with the bacteria 60 days after receiving cercariae of $S$. mansoni. More recently Teixeira et al. (1996) have confirmed and extended our initial findings. Lima and Maluf (1995) have also reported a case in a patient with chronic schistosomiasis.

The medical charts of 50 patients with pyogenic liver abscesses who were admitted to three general hospitals of Belo Horizonte, State of Minas Gerais, in Brazil, during a period of ten years, were reviewed retrospectively by Lambertucci et al. (1991b). Demographic information, chief complaints, clinical and laboratory findings, and response to treatment were recorded. The age range varied from 2 to 79 years ( $41 \%$ were younger than 15). The main presenting complaints were fever and abdominal pain. Eosinophilia was observed in 15 cases $(30 \%)$. Parasitological stool examination 
was obtained from 28 patients with liver abscesses, and in $20(71 \%)$ the following agents were identified in the stools: S. mansoni (36\%), Strongyloides stercoralis (21\%), Ascaris lumbricoides (18\%), Entamoeba histolytica (4\%). Ultrasonography had a major role in the diagnosis of liver abscesses and in treatment, directing the percutaneous drainage of the purulent collections. Culture of the material obtained during surgery or by percutaneous puncture in 30 patients revealed: $S$. aureus (14 cases), $S$. viridans (2 cases), Gram-negative bacteria (5 cases), the association of Gram-positive and Gramnegative ( 2 cases). Two out of the 5 patients submitted to liver biopsy had the necrotic-exudative granulomata of schistosomiasis. The authors conclude that schistosomiasis and migrating larvae of other parasitic diseases (A. lumbricoides, $S$. stercoralis, Toxocara) may be a predisposing factor for pyogenic liver abscesses.

Some mechanisms have been proposed as a probable explanation for the association of schistosomiasis and pyogenic liver abscesses: (1) liver necrosis caused by eggs or dead worms of $S$. mansoni could be colonized by bacteria; (2) there is transient impairment of the cell mediated immunity in the acute phase of schistosomiasis in animal models (Araújo et al. 1977); (3) the literature contains several reports of cases of recurrent infections caused by $S$. aureus in the presence of high IgE levels in the serum (Galandiuk et al. 1995, Lambertucci 1996), and high serum IgE levels have been reported in acute schistosomiasis.

We have noticed regional differences in the clinical presentation of liver abscesses in South America when compared to northern countries (Huang et al. 1996). Nowadays, in developed countries, pyogenic liver abscesses are more often found in individuals of middle age or older, especially those who have underlying biliary tract diseases with obstruction and bile stasis that favour infection. Before antibiotics, appendicitis with bacterial seeding of the liver through the portal vein was a frequent cause. Pyogenic liver abscesses secondary to intestinal diseases are well recognized in patients with a variety of disorders including Crohn's disease and diverticulitis. Penetrating wounds to the liver may also lead to abscesses. Pyogenic liver abscess is frequenly polimicrobial. Gram-negative enteric bacteria, especially E. coli, Klebsiella pneumoniae, Streptococcus fecalis, and Proteus vulgaris, are major contributors (McDonald et al. 1984). Infection by multiple organisms is frequent.

Also, in developed countries, hepatic abscesses are rare in children but, when present, they occur up to 5 years of age and can be associated with thrombophlebitis of the umbilical vein, abdominal traumatism and immunosuppressive disease (Moss \& Pysher 1981).

In some areas of Brazil, however, pyogenic liver abscesses have been more frequently observed in young individuals (mostly under 15 years of age), and $S$. aureus has been the main bacteria cultured of aspirates from the abscesses. Acute schistosomiasis, and migrating larvae of other parasitic diseases (Ascaris, Strongyloides, Toxocara) have been implicated as facilitating factors in the genesis of pyogenic liver abscesses and staphylococcal infections (Lambertucci et al. 1990, Musso et al. 1996, Teixeira et al. 1996, Lambertucci 1996).

\section{ASSOCIATION WITH HIV}

The basis for expecting interactions between HIV infection and schistosomiasis derives largely from our knowledge of the immunology of schistosomiasis and of the effects of HIV on the immune system. HIV infection causes progressive disruption of the immune system with a gradual fall in the number of CD4-positive lymphocytes and increasing functional impairment of cell-mediated immunity. In vitro, HIV becomes activated when host lymphocytes or macrophages are stimulated by antigens or mitogens.

Data on the behaviour of schistosomiasis in the immunosuppressed host are rather scarce. It is possible to consider at least four areas of clinical interest concerning this new scenario (Lambertucci $\&$ Neves et al. 1993): (1) depression of cell-mediated immune response in the host diminishes granulomatous response to $S$. mansoni eggs. Mice experimentally infected with $S$. mansoni and immunosuppressed by drugs or thymectomy develop diffuse and severe hepatitis. Climent et al. (1994) reported the postmortem histopathological changes in 100 patients with AIDS who died in Puerto Rico from 1982 to 1991 . Ten out of their 100 patients had schistosomiasis mansoni and all showed minimal inflammatory or granulomatous tissue reaction. Lambertucci and Neves (1993) reported the complete absence of granulomatous response to eggs and severe hepatic necrosis in a patient who died with the Salmonella-S. mansoni association and was found at autopsy to have, in addition, disseminated tuberculosis and $S$. mansoni eggs scattered in multiple organs. The migration of worms to different organs in the human body may explain the finding of a great number of eggs in unusual places. This hypothesis implies that the immune system is important in keeping the adult worms of S. mansoni confined to the mesenteric vessels; (2) Lambertucci and Rayes (unpublished observation) have examined the cases of two young men with Salmonella bacteraemia, active schistosomiasis and the acquired immunodeficiency syndrome. Liver 
biopsy specimens obtained during laparoscopy of one patient revealed in the periportal area poorly formed granulomata around $S$. mansoni eggs and hepatitis of moderate intensity. Treatment of schistosomiasis alone induced consistent clinical improvement and eventual cure of both Salmonella and S. mansoni infections. Recognition of the Salmonella-S. mansoni association in patients with AIDS should not be easy because the presenting signs and symptoms (diarrhoea, prolonged fever, hepatosplenomegaly and weight loss) have been described in patients with AIDS alone. The association may help to explain the high prevalence of Salmonella bacteraemia in AIDS patients from Africa (Gilks et al. 1992); (3) egg output decreases sharply in mice experimentally infected with $S$. mansoni and immunosuppressed by drugs or thymectomy (Doenhoff et al. 1986). A well formed granuloma facilitates the migration of eggs in the host tissues. Without granuloma formation, $S$. mansoni eggs do not reach (or only in small numbers) the gut lumen. Diagnosis of schistosomiasis, based on parasitological stool examination, in this context, should be reexamined. Rectal or liver biopsies, and ELISA tests for circulating antigens would represent an alternative to stool examination in such cases. Studies in patients with AIDS and low CD4 cell counts are mostly needed either to confirm or exclude this interesting hypothesis; (4) in mice infected with $S$. mansoni and immunosuppressed by thymectomy, the efficacy of schistosomicides is decreased (Lambertucci et al. 1989, Doenhoff et al. 1991). Failure to respond to oxamniquine or praziquantel, in the usual doses, is to be expected in the immunocompromised host infected with $S$. mansoni. So far, this possibility in AIDS patients remains speculative.

\section{REFERENCES}

Araújo FG, Coelho PMZ, Pereira LH, Pellegrino J 1977. Schistosoma mansoni: impairment of the cell-mediated immune response in mice. Clin Exp Immunol 28: 289-291.

Barsoum RS, Bassily S, Baligh OK, Eissa M, El-Sheemy N, Affify N, Hassaballa AM 1977. Renal disease in hepatosplenic schistosomiasis: a clinicopathological study. Trans $R$ Soc Trop Med Hyg 71: 387-391.

Bassily S, Farid Z, Higashi GI, Kamel IA, El-Masry MA, Watten RH 1979. Chronic hepatitis B antigenaemia in patients with hepatosplenic schistosomiasis. J Trop Med Hyg 82: 248-251.

Chen MG, Mott KE 1988. Progress in assessment of morbidity due to Schistosoma mansoni infection. Trop Dis Bull 85: R1-R56.

Climent C, DeVinatea ML, Lasala G, Sing OI, Vélez R, Colón L, Mullick FG 1994. Geographical pathology profile of AIDS in Puerto Rico: the first decade. Modern Pathol 7: 647-651.
Coelho HSM, Fogaça HS, Hercules HC, Carneiro AJV, Lemme EMO, Toledo JA 1985. Chronic hepatitis associated to hepatosplenic schistosomiasis. Clinical-evolutive study of 19 cases. GED 4: 41-44.

Colley DG, Garcia AA, Lambertucci JR, Parra JC, Katz N, Rocha RS, Gazzinelli G 1986. Immune responses during human schistosomiasis. XII. Differential responsiveness in patients with hepatosplenic disease. Am J Trop Med Hyg 35: 793-802.

Doenhoff MJ, Hassounah O, Murare H, Bain J, Lucas S 1986. The schistosome egg granuloma: immunopathology in the cause of host protection or parasite survival? Trans $R$ Soc Trop Med Hyg 80: 503-514.

Doenhoff MJ, Modha J, Lambertucci JR, McLaren DJ 1991. The immune dependence of chemotherapy. Parasitol Today 7: 16-18.

Domingo EO, Lingao AL, Tiu E, Lao JY, Olveda RM 1983. HBV exposure and HBsAg positive rates in schistosomiasis japonica: study in a Philippine community endemic for both infections. Southeast Asian J Trop Med Publ Hlth 14: 456-462.

Eltoum IA, Ghalib HW, Al-Gadir AF, Suleiman SM, Homeida MMA 1991. Lack of association between schistosomiasis and hepatitis B virus infection in Gezira-Managil area, Sudan. Trans $R$ Soc Trop Med Hyg 85: 81-82.

Farid Z, Trabolsi B, Hafez A 1984. Escherichia coli bacteraemia in chronic schistosomiasis. Ann Trop Med Parasitol 78: 661-662.

Galandiuk S, Gardner SA, Heinzelmann M 1995. Constituent analysis may permit improved diagnosis of intra-abdominal abscess. Am J Surg 171:335-339.

Ghaffar YA, Kamel M, El-Sobky M, Bahnasy R, Strickland GT 1989. Response to hepatitis B vaccine in infants born to mothers with schistosomiasis. Lancet 2: 272.

Ghaffar YA, Kamel M, Wahab A, Dorgham LS, Saleh MS, El Deed AS 1990. Hepatitis B vaccination in children infected with Schistosoma mansoni: correlation with ultrasonographic data. Am J Trop Med Hyg 43: 516-519.

Gilks CF, Otieno LS, Brindle RJ, Newnham RS, Lule GN, Were JBO, Simani PM, Bhatt SM, Okelo GBA, Waiyaki PG, Warrel DA 1992. The presentation and outcome of HIV-related disease in Nairobi. $Q J$ Med 82: 25-32.

Graham JG, Orr JL 1950. Hepatic abscess associated with visceral schistosomiasis. Lancet 1: 714-716.

Huang CJ, Pitt HA, Lipsett PA, Osterman FA, Lillemoe KD, Cameron JL, Zuidema GD 1996. Pyogenic hepatic abscess. Changing trends over 42 years. Ann Surg 223: 600-607.

Hyams KC, EL Alamy MA, Pazzaglia G, El Ghorab NM, Sidhom O, Habib M, Dunn MA 1986. Risk of hepatitis B infection among Egyptians infected with Schistosoma mansoni. Am J Trop Med Hyg 35: 10351039.

Lambertucci JR 1993. Schistosoma mansoni: pathological and clinical aspects, p.195-225 In P Jordan, G Webbe, RF Sturrock (eds), Human Schistosomiasis, Cab International, Wallingford.

Lambertucci JR 1995. Treatment of schistosomiasis: 
gathering stones together. Mem Inst Oswaldo Cruz 90: 161-164.

Lambertucci JR 1996 Hyperimmunoglobulinemia E, parasitic diseases and staphylococcal infection. Rev Soc Bras Med Trop 29: 407-410.

Lambertucci JR, Neves J 1993. Associação SalmonellaSchistosoma-Mycobacterium: relato de um caso. Arq Bras Med 67: 53-54.

Lambertucci JR, Godoy P, Neves J, Bambirra EA, Ferreira MD 1988. Glomerulonephritis in Salmonella-S. mansoni association. Am J Trop Med Hyg 38: 97-102.

Lambertucci JR, Marinho RP, Ferreira MD, Neves J 1985a The value of the Widal test in the diagnosis of prolonged septicemic salmonellosis. Rev Inst Med Trop São Paulo 27: 82-85.

Lambertucci JR, Marinho RP, Ferreira MD, Neves J, Pedroso ERP 1985b. Therapeutic efficacy of oral oxamniquine in the treatment of Salmonella-S. mansoni association. Rev Inst Med Trop São Paulo 27: 33-39.

Lambertucci JR, Modha J, Doenhoff MJ 1989. Schistosoma mansoni: the therapeutic efficacy of oxamniquine is enhanced by immune serum. Trans $R$ Soc Trop Med Hyg 83: 362-363.

Lambertucci JR, Pereira FAS, Marinho RP, Neves J, Ferreira MD 1991a. Associação Salmonella-S. mansoni: análise de 104 casos. Rev Soc Bras Med Trop 24 (Suppl. I): 76.

Lambertucci JR, Teixeira R, Pereira FAS, Brant CQ, Pinto LW 1991b. Abscesso piogênico do fígado: análise de 50 casos. Rev Soc Bras Med Trop 24 (Suppl. II): 83.

Lambertucci JR, Teixeira R, Navarro MMM, Coelho PMZ, Ferreira MD 1990. Liver abscess and schistosomiasis. A new association. Rev Soc Bras Med Trop 23: 239-240.

Lima VC, Maluf FC 1995. Schistosomiasis: predisposing cause for the formation of hepatic abcesses? Rev Inst Med Trop São Paulo 37: 277-280.

Lo Verde PT, Amento C, Higashi GI. 1980. Parasiteparasite interaction of Salmonella typhimurium and Schistosoma. J Inf Dis 141: 177-185.

Lyra GL, Rebouças G, Andrade ZA 1976. Hepatitis B surface antigen carrier state in hepatosplenic schistosomiasis. Gastroenterology 71: 641-645.

Madwar MA, El-Tahawy M, Strickland GT 1989. The relationship between uncomplicated schistosomiasis and hepatitis B infection. Trans $R$ Soc Trop Med Hyg 83: 233-236.

McDonald MI, Corey GR, Fallis HA, Durack DT 1984.
Single and multiple pyogenic liver abscesses. Medicine 63: 291-302.

Morrow RH, Colebunders RL, Chin J 1989. Interactions of HIV infection with endemic tropical diseases. AIDS 3 (Suppl 1): S79-S87.

Moss TJ, Pysher TJ 1981. Hepatic abscess in neonates. Am J Dis Child 135: 726-728.

Muniz-Junqueira M, Tavares-Neto J, Prata A, Tosta CE 1996. Antibody response to Salmonella typhi in human schistosomiasis mansoni. Rev Soc Bras Med Trop 29: 441-445.

Musso C, Pereira FEL, Dettogni RV, Ferreira MAB 1996. Abscesso piogênico do fígado e esquistossomose no Estado do Espírito Santo. Rev Soc Bras Med Trop 29: 359-362.

Neves J, Martins NRLL 1967. Long duration of septicaemic salmonellosis: 35 cases with 12 implicated species of Salmonella. Trans R Soc Trop Med Hyg 61: 541-552.

Ottens H, Dickerson G 1972. Studies on the effects of bacteria on experimental schistosome infections in animals. Trans R Soc Trop Med Hyg 66: 85-107.

Pereira LMMB, McFarlane BM, Massarolo P, Saleh MG, Bridger C, Spinelli V, Mies S, McFarlane IG 1997. Specific liver autoreactivity in schistosomiasis mansoni. Trans R Soc Trop Med Hyg 91:310314.

Rocha H, Kirk JW, Heary CD 1971. Prolonged Salmonella bacteraemia in patients with Schistosoma mansoni infection. Arch Int Med 128: 254-257.

Rocha H, Motta JG, Rebouças G 1968. Características da infecção por Escherichia coli em camundongos com esquistossomose mansoni. Rev Inst Med Trop São Paulo 10: 299-304.

Salih SY, Abu Sabaa H, Abu Asha H, Abdel Satir A 1977. Salmonellosis complicating schistosomiasis in Sudan. J Trop Med Hyg 80: 14-18.

Serufo JC 1997. A Associação entre a Hepatite B e a Esquistossomose Mansônica: uma Falácia Ecológica, Thesis, Faculty of Medicine, Federal University of Minas Gerais, 204 pp.

Serufo JC, Lambertucci JR 1977 Esquistossomose e hepatites virais: uma revisão. Rev Soc Bras Med Trop 30: 313-322.

Teixeira RS, Bina JC, Barreto SH 1976. Bacteria infection of long duration due to genus Escherichia in a patient with S. mansoni. Rev Med Bahia 22: 70-74.

Teixeira R, Ferreira MD, Coelho PMZ, Brasileiro Filho G, Azevedo Junior GM, Lambertucci JR 1996. Pyogenic liver abscesses and acute schistosomiasis mansoni: report on 3 cases and experimental study. Trans $R$ Soc Trop Med Hyg 90: 280-283. 

Schistosomiasis and Associated Infections - JR Lambertucci et al. 